профессионально-педагогический университет; Уральский юридический институт МВД России. Екатеринбург, 2019. - 93 с. - Текст: непосредственный.

3. Кузнецова А. В. О системном подходе в профилактике преступности несовершеннолетних [Текст] / А. В. Кузнецова // Право и образование. 2011. № 2. С. 145-150.

4. Лебедева А. А. Административный надзор, как один из способов альтернативного наказания [Текст] / А. А. Лебедева // Союз криминалистов и криминологов. 2018. № 4. С. 91-95.

5. Поликарпова Е. В. О некоторых вопросов осуществления профилактики преступлений и административных деликтов участковым уполномоченным полиции в отношении лиц ранее судимых [Текст] / Е.В.Поликарпова // Вестник экономической безопасности. 2020. № 1. С. 207210.

6. Приказ МВД РФ от 31 декабря 2012 г. № 1166 "Вопросы организации деятельности участковых уполномоченных полиции" (с изменениями и дополнениями) [Электронный ресурс] // Режим доступа: http://base.garant.ru/70344228/ (дата обращения: 02.01.2021)

7. Приказ МВД РФ от 29 марта 2019 г. № 205 «О несении службы участковым уполномоченным полиции на обслуживаемом участке и организации этой деятельности» [Электронный ресурс] // Режим доступа: https://www.garant.ru/products/ipo/prime/doc/72188134/ (дата обращения: 02.01.2021)

8. Трудовой кодекс Российской Федерации [Электронный ресурс] // Режим доступа: http://www.consultant.ru/document/cons_doc_LAW_34683/ (дата обращения: 12.01.2021).SEsep.

9. Федеральный государственный образовательный стандарт высшего образования - специалитет по направлению подготовки 40.05.02 «Правоохранительная деятельность» / утв. Приказом Минобрнауки России от 16 ноября 2016 года № 1424 [Электронный ресурс] // Режим доступа: http://www.consultant.ru/document/Cons_doc_LAW_208501/ (дата обращения: 05.01.2021).

\title{
Ци Хаймань \\ Сравнительно-исторический метод в изучении повести Николая Островского «Как закалялась сталь»
}

Московский педагогический государственный университет (Россия, Москва)

doi: $10.18411 / l j-02-2021-175$

idsp: ljournal-02-2021-175

\section{Аннотоция}

С момента своего создания «Как закалялась сталь» произвело широкий спектр влияний по всему миру, особенно в Китае, где социальная система очень похожа на Советский Союз. «Песня молодости» - репрезентативная работа китайского писателя Яна Мо. Это роман об истории революции и росте интеллигенции. В этой статье будет использован сравнительно-исторический метод Жирмунского, чтобы проанализировать сходства и различия между двумя вышеупомянутыми статьями с точки зрения сюжета и содержания.Изучение двух китайских и русских романов на одну и ту же тему имеет большое историческое значение для изучения китайской и русской культуры.

Ключевые слова:сравнение; Песня молодости; как закалялась сталь

Сравнительо-исторический метод - методика анализа, помогающая осознать сходство и различия явлений словесно-художественного творчества, относящихся к разных национальным литературам.

Рассматриваются идеи крупнейших русских литературоведов дореволюционного периода в России, заложивших основы сравнительного литературного исследования. Устанавливается, что современное представление о сравнительном литературоведении во многом определяют идеи, заложенные русскими учеными А.Н. Веселовским и В.М. Жирмунским, разработавшими отдельные литературоведческие аспекты на материале различных литературных фактов и явлений. Доказывается, что на основе идей русских ученых компаративное литературоведение формировалось в рамках господствовавшей в тот период культурно-исторической школы, 
Жирмунский является одним из основателей сравнительной литературы в Советском Союзе, и за полвека своей научной карьеры он органично сочетал изучение местных особенностей с изучением универсальных законов, отражающих академическое мышление от анализа до всесторонности.Жирмунский счтал,что сравнение, т. е. установление сходств и различий между историческими явлениями и историческое их объяснение, представляет, обязательный элемент всякого исторического исследования. Сравнение не уничтожает специфики изучаемого явления (индивидуальной, национальной, исторической); напротив, только с помощью сравнения, т. е. установления сходств и различий, можно точно определить, в чем заключается эта специфика. Это справедливо даже по отношению к простому сопоставлению сходных общественных явлений, Но путь научного-исследования ведет от простого сопоставления, констатирующего сходства, к их историческому объяснению.Разумеется, сравнение подобного рода представляет не особый метод: в собственном смысле, поскольку различие методов (то, что мы называем методологией) есть различие принципов научного исследования, обусловленных мировоззрением данного научного направления. Сравнение относится к области методики, а не методологи и: это методический прием исторического исследования, который может применяться с разными целями и в рамках разных методов, однако является необходимым для любой исследовательской работы в области исторических наук.

Основной предпосылкой сравнительно-исторического изучения литератур разных народов является марксистское понимание единства и закономерности общего процесса социально-исторического развития человечества, которым обусловлено и закономерное развитие литературы или искусства как идеологической надстройки. вопрос о сходных путях развития литературы разных народов, об историкотипологических аналогиях литературного процесса все время перекрещивается с вопросом о международных литературных взаимодействиях и влияниях. Невозможность полностью выключить эти последние вполне очевидна. История человеческого общества фактически не знает примеров абсолютно изолированного социального и культурного (а следовательно, и литературного) развития при отсутствии взаимодействия между отдельными его участками. Чем культурнее народ, тем интенсивнее его связи и взаимодействия с другими народами. Напомним слова Маркса в предисловии к "Капиталу": "Всякая нация может и должна учиться у других".

Сказанное относится и к специальной области литературы. Ни одна великая национальная литература не развивалась вне живого и творческого взаимодействия с литературами других народов。

Подобно «Как закалялась сталь», «Песня молодости» также имеет некоторые автобиографические черты. В романе мы можем найти основу для написания, основанную на жизненном опыте времени автора. Создание этой работы также глубоко вдохновле"но духом Павла. Роман в полной мере демонстрирует творческий замысел автора через образы персонажей с определе“нными индивидуальными особенностями, извилистый художественный сюжет, сформированный действиями персонажей, яркий художественный язык и различные интригующие художественные приемы.

C точки зрения структуры сюжета, «Песня молодости» основана на идеологическом процессе как на главной линии творения. «Рост Линь Даоцзин претерпел три основных поворотных момента. Она сопротивлялась браку и вышла из феодальной семьи, ища индивидуального освобождения, вступая в контакт с революцией и порывая с индивидуалистическим Юй Юнцзе. Революционное обучение, идеологическая трансформация и вступление в Коммунистическую партию. В конце концов, он избавился от отметин помещичьего класса и настроений мелкой буржуазии и на практике стал настоящим пролетарским революционным борцом. Это типичный путь роста мелкобуржуазного интеллектуала, который превращается в стойкого революционера.Сюжет разворачивается между инцидентом« 18 сентября »и 
движением« 9 декабря ». Этот период является периодом социальных и политических изменений, и эти события также являются решающим фактором в жизненном пути персонажей. .

Постоянная тема-революция и любовь

Судя по содержанию работ, «Как закалялась сталь» и «Песня молодости» оба описывают процесс революционного роста героя, но повествовательный способ отличается. В «Как закалялась сталь» главный герой Пол родился на дне общества, и он ненавидел всех богатых людей. В процессе своего участия в революции, хотя он также был просвещен и руководствовался матросом Жухрай, он наконец встал на революционную дорогу, потому что был арестован из-за случайной возможности спасти Жухрая. Покинув родной город, он участвовал в революции и выдержал различные испытания в революции.

В «Песня молодости» революционный процесс роста Линь Даоцзин - это в основном идеологическое просвещение. Она выросла в образованной среде и часто занималась глубоким саморефлексией. «Я оказалась мелкобуржуазным революционером-провидцем, Я понимаю, что революция - розовая или серая, но кровавая и ярко-красная перед жестокой реальностью ... Оказывается, мое тело было отпечатано белыми отметками классом хозяев и эксплуататорским классом. И играть так глубоко в мою душу ".

С точки зрения любви, Пол и Линь Даоцзин, кажется, выбрали революционный путь любви.

Конкретно проанализировав, мы обнаружим, что разрыв Павла с Тони является признаком зрелости Павла после длительной практики революционной борьбы. Разделение Линь Даоцзин и Юй Юнцзэ на лицо происходит из-за политических разногласий, но на самом деле это Поскольку Линь Даоцзин не желает жить посредственной жизнью, он стремится найти страсть жизни и романтику любви в революции.

Однажды Пол влюбился в Тоню, дочь лесного офицера, их роман был полон романтики, и Тоня рискнул прикрыть Пола. Но с течением времени буржуазный индивидуализм Тоня показала, что она не желает отпускать свою аристократическую идентичность и участвовать в борьбе рабочего класса. Тем не менее, Павел в это время стал более зрелым после долгого периода практики революционной борьбы. Когда он понял, что гедонистические мысли Тони не могут быть очищены, он решил порвать с ней, что, несомненно, показало твердую решимость зрелого большевика. Принцип и великая настойчивость. Кроме того, мы можем увидеть богатство и глубину внутренних эмоций Павла из скромного стремления Павла к любви Риты и его искренним чувствам к Тоне. Однако он никогда не противостоял своим эмоциям и революциям. Когда он обнаружил, что у Риты уже есть муж, он был очень грациозен и сказал: «Несмотря ни на что, я все равно получаю больше, чем мы потеряли». Он и Рита Цветку любви на самом деле суждено засохнуть до того, как он расцветет, но от него он «полностью показывает новый благородный дух пролетариата».

Будь то Пол или Рита, они тесно связали свое личное счастье и радость с победой всей коммунистической молодежи. Это пара близких соратников и два пролетарских героя, которые правильно относятся к любви и дружбе. По мнению Павла, партия и революция являются единственными критериями для проверки любви. Когда он официально был с Тоней, он проповедовал своей жене: «Наш союз должен продолжаться, пока вы не станете настоящим человеком и не станете одним из нас». Во-первых, я должен помочь вам сделать это, или я буду бесполезным. До этого мы не должны разрушать наш союз. Как только вы вырастете, вы можете быть свободны от любых ограничений. Кто знает, может быть, я когда-нибудь стану полной тратой. Вы помните, в то время я никогда не потащу вас вниз. «Тоня приняла эту благородную любовь. Ее любовь» не только заботится о нежной жизни своего мужа, но и превращает 
любовь ее мужа в себя в мотив и активно участвует в революции. «Исходя из этой цели Несмотря на собственную боль, Павел помог Тоне стать полноценным членом партии и стал членом городского совета и заводского комитета.

Линь Даоцзин - «простая, одинокая красивая девушка». Такая женщина создает впечатление, что она более уязвима и нуждается в жалости и помощи. Юй Юнцзе был первым человеком в жизни Лин Даоцзин. Когда Лин Даоцзин решил покончить с собой, чтобы показать свое сопротивление этому уродливому миру, Юй Юнцзэ спасла ей жизнь. Линь Даоцзин был глубоко привлечен темпераментом «рыцаря и поэта» Юй Юнцзе, как сказал сам Лин Даоцзин: «Страстный рыцарь, талантливый молодой человек». В романе, среди трех мужчин, которые спорят с Линь Даоцзин, только Юй Юнцзэ рассматривает Линь Даоцзин как чистую женщину.В его глазах Линь Даоцзин женщина и жена. И не должно быть ничего другого, потому что «она его». Как только появился Лу Цзячуань, он произвел глубокое впечатление на Линь Даоцзин: он зрелый марксист-ленинец. Если любовь Юй Юнцзэ к Линь Даоцзин вызвана страстью между мужчинами и женщинами, тогда, когда Лу Цзячуань здесь, это становится Революционная причина - первая. Когда Дай Ю обвинила Лу Цзячуаня и Линь Даоцзина в том, что они слишком близки, сестра Лю защищалась и сказала: «Я знаю ее и немного понимаю о ее ситуации. Это интеллектуал, который боролся в старом обществе и жаждал спасения партии. Мы Ей нужно помогать и заботиться. «Лу Цзячуань поддерживал связь с Линь Даоцзин с идеями« помогать »и« совершенствоваться ». «Мы должны помочь такой девушке, которая имеет чувство справедливости и борьбы, и должна взять ее за руку, а не потопить». Тем не менее, мы все еще можем видеть, что у Лу Цзячуаня есть чувства к Линь Даоцзин, но в глазах Лу Цзячуаня скучно тратить время на эмоциональные проблемы. Если неудача Линь Даоцзин и Юй Юнцзэ не нашла политического места встречи, то ее неудача с Лу Цзячуанем - отказаться от любви к революционной политике. Поэтому ни Ю Юнцзе, ни Лу Цзячуань не смогли понять истинное сочетание политики и любви. До появления Цзян Хуа этот человек заставил Линь Даоцзин официально начать коммунистическое дело. Хотя он и Лу Цзячуань также являются сильными пролетарскими революционными борцами, они также проявляют остроумие, хладнокровие и изощренность в революционных рядах, но в конце концов они имеют разные личностные характеристики. Люди отличают Цзянхуа и Лу Цзячуаня от деятельности новых персонажей не только потому, что Цзянхуа выше, но и, что более важно, хотя Лу Цзячуань рассматривает вещи дотошно и спокойно, по сравнению с последним Цзянхуа У него более стабильная и спокойная сторона. Хотя речь и манеры Лу Цзячуана также очень сердечные и полные энтузиазма, по сравнению с Цзян Хуа, Цзян Хуа более добрый и простой. Вид медлительности слов, когда он говорит Лу Цзячуаня, и насколько Немного изящества и Цзян Хуа, автор дал больше рабочих темперамент. Когда ДаоЦзин знал ЦзяХуа, он уже был учителем начальной школы в сельской местности.

В течение тысячелетий крестьянская проблема была основной проблемой китайской революции. Поэтому, когда Линь Даоцзин глубоко ушел в деревню, он действительно коснулся специфических проблем китайской революции и постепенно сформировал зрелую революционную мысль. Линь Даоцзин сказал Цзян Хуа: «Я дочь помещика и дочь фермера-арендатора, поэтому у меня белые кости и черные кости». В русском фольклоре белые кости представляют дворян, а черные кости представляют рабов и трудящихся. Такое творение, несомненно, сделало персонажа «двойственным» независимо от идентичности или мышления, проложив ему путь к пролетариату и присоединиться к революционному делу. Однако, внимательно прочитав текст, мы обнаружим, что «Песня молодости» время от времени активно раскрывает «мелкобуржуазные чувства», одновременно активно изменяя мировоззрение, такие как слабость Линь Даоцзин в любви, нежность боли людей и право Революционная 
нереальная фантазия и личный героизм и т. д. «Мелкобуржуазные настроения» также часто называют «мелкобуржуазными настроениями», и этот термин подвергался жесткой критике во время культурной революции. В «Песня молодости» "мелкобуржуазные чувства" перепрыгивают через рациональное мышление автора и время от времени к читателю обращаются к читателю, хотя это и не является изначальным намерением автора.

Художественные характеристики работы

Оба романа относятся к категории революционной литературы, потому что они основаны на предпосылке революции. В «Как закалялась сталь» главный герой Пол продолжал расти в революции и, наконец, превратился в главную силу в революционной битве. Весь смысл романа заключается в том, что только выбрав революцию, мы действительно сможем встать на правильный путь.

Линь Даоцзин стремится присоединиться к революции, и его желание получить помощь от Коммунистической партии так сильно, но его понимание революции еще не полностью.

«Я давно хотела спутать эту жизнь с посредственностью, лучше умереть энергично. Я не боюсь смерти, я ничего не боюсь». Однако Лу Цзячуань исправил ее концепцию,Лу Цзячуань пристально посмотрел на нее.

Красивое лицо, полное детства и страсти, с этого лица он полностью доверял девушке, живущей в грязи противоречий. После паузы он посмотрел ей прямо в глаза и сказал: «Разве героическая идея умереть в Синьцзяне не изменилась?» Она улыбнулась.

«Линь, вы не правы. Участие в революции - это не то, чтобы просить нас умереть, а чтобы заставить нас жить более осмысленно, чтобы миллионы угнетенных людей могли жить счастливо. Почему бы не подумать о смерти, прежде чем что-то делать? Неправильно".

Как сказала автор: «Я создала характер, цель и мотивацию Линь Даоцзин ... Я хочу выразить величие партии и партии через процесс ее - Линь Даоцзин, от индивидуалистического интеллектуала до пролетарского солдата. Глубоко в сердцах людей, роль партии в руководстве китайской революции.Я знаю, что в литературных произведениях выражение таких тем и идей может осуществляться разными способами и разными способами, и я могу использовать это только из своей более знакомой жизни. Я сам чувствую самые глубокие вещи, чтобы выразить. Автор давно признала, что Линь Даоцзин не является идеальным примером, она - просто обычный китаец, которая получила образование в партии и спас ее, прежде чем встать на путь революции. Один из интеллектуалов. "

В романе Ван Мень «Песня молодежи» это было написано так: «Переверните красную лакированную кожу своего дневника и посмотрите на председателя Мао. Они часто пишут слова своих любимых книг в стиле сценария для взрослых: : Самое дорогое у человека- это жизнь. Она даётся ему один раз, и прожить её надо так, чтобы не было мучительно больно за бесцельно прожитые годы, чтобы не жёг позор за подленькое и мелочное прошлое, чтобы, умирая, смог сказать: вся жизнь и все силы были отданы самому прекрасному в мире - борьбе за освобождение человечества. И надо спешить жить. Ведь нелепая болезнь или какая-либо трагическая случ.”

\section{Заключение}

Можно сказать, что «Как закалялась сталь» и «Песня молодости» оказали большое влияние на интеллектуальную молодежь Китая. Революции и революционеры, описанные в этих двух работах, глубоко запечатлены в умах людей.Почти все писатели в современных литературных кругах Китая испытали влияние советской литературы.

Так называемая «тысяча Гамлетов в глазах тысячи читателей», эстетическая концепция и жизненный опыт каждого человека различны, и суждение о литературных произведениях также неизбежно разделяется. После того, как роман был опубликован, 
он сразу привлек внимание читателей. Главный герой Линь Даоцзин, Лу Цзячуань, Лин Хун, Цзян Хуа и другие блестящие коммунистические деятели оставили глубокое впечатление на каждого читателя. Подавляющее большинство читателей считают, что «Песня молодости» точно отражает черты времени, формируя образ группы героических революционных воинов, и является похвальным романом.

Чтобы изучать литературные произведения, мы должны сначала изучить жизнь, отраженную в этих произведениях. Без правильного понимания предыстории произведений искусства мы не можем сделать правильную оценку произведений искусства.

В этой статьи сравнительно изучил характер персонажей, художественные характеристики и т. д. Этих персонажей и описал персонажей двух разных миров в двух романах поэтапно. Читатели неизбежно свяжут их вместе. В революционной войне они Они только очень обычные члены. Независимо от того, во время советской революции или китайской революции, группа борцов-революционеров, таких как Павел, появлялась каждый день. Они боятся трудностей и жертв и бросаются на передовые рубежи революционной войны - все эти образы служат примером для будущих поколений.

\section{***}

1. Я Мо. Песня молодости.М.Издательство народной литературы, 1978

2. Ван Мэн.Да здравствует молодежь. М.Издательство народной литературы, 1979

3. Л.Ф.Ершов,История русской советской литературы,Москва:высшая школа, 1982

4. В.В.Агеносов,Русская литература 20 века,Москва:изд.дом 《Дрофа》,1999

5. Сравнительное литературоведение и проблема литературных влияний „Изв. АН СССР, ООН, 1937 , № 3, стр. 383-403.

6. Литературные отношения Востока и Запада как проблемы сравнительного литературоведения „Ленинградский гос. ун-т. Тр. юбилейной научной сессии, секция филолог, наук, 1946, стр. $152-$ 178.

7. Н.Островский.Как закалялась сталь.1975, [электронный ресурс],Режим доступа:https://librebook.me/kak_zakalialas_stal

8. Жирмунский В.М.Сравнительное литературоведение. М.Восток и запад.Л.:Наука,1979.

9. Жирмунский В.М.Гете в русской литературе. М. Л.:ГИХЛ,1937.

10. Жирмунский В.М.Поэтика русской поэзии. М.Азбука-классика, 2001.

\section{Чимаров С.Ю.}

\section{Актуальные проблемы воспитания личного состава органов внутренних дел в условиях динамичного продвижения современных Интернет-технологий}

Санкт-Петербургский университет МВД России (Россия, Санкт-Петербург)

doi: $10.18411 / l j-02-2021-176$

idsp: ljournal-02-2021-176

\section{Аннотация}

В статье представлен сравнительный анализ зарубежной и отечественной практик регулирования правил цифрового обмена сотрудников органов внутренних дел на основе действующих нормативных положений, закрепляющих пределы дозволенного. Выявляя общность концептуальных подходов к оценке вопросов цифровой бдительности, автор акцентирует внимание на важности целенаправленной воспитательной работы с каждым сотрудником органов внутренних дел, в части воспитания осознанного отношения к процессу саморегулирования своей цифровой активности.

Ключевые слова: воспитание, органы внутренних дел, цифровая бдительность, цифровая безопасность, цифровой след, социальная сеть, сетевое пространство. 